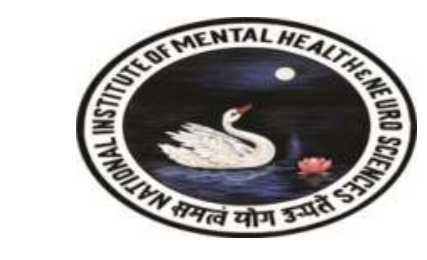

\title{
Determinants of Family Functioning in Caregivers of Persons with OCD
}

Nithyananda S. Murthy ${ }^{1,2}$, Srinivas Balachander ${ }^{1,3}$, Nirmala BP ${ }^{2}$, R. Dhanashekara Pandian ${ }^{2}$, ShyamSundar Arumugham ${ }^{1,3}$, YC Janardhan Reddy $^{1,3}$

- OCD Clinic, National Institute of Mental Health \& Neuro-Sciences (NIMHANS), Bangalore

- Department of Psychiatric Social Work, NIMHANS Bangalore

- Department of Psychiatry, NIMHANS, Bangalore

Background: Though obsessive-compulsive disorder (OCD) is known to cause significant burden to patients and their caregivers, there is limited data on its impact on family functioning. The current study examines the determinants of family functioning in caregivers of persons with OCD.

Objectives: To study Family Functioning (FF) and potential determinants including stress levels, resilience, psychiatric morbidity (depression and anxiety), socio-occupational functioning and family accommodation in caregivers of persons with OCD

Methods: 200 DSM-5 OCD patients were evaluated using Mini International Neuropsychiatric Interview (MINI) and the YaleBrown Obsessive-Compulsive Scale (YBOCS). Their primary caregivers were evaluated using the MINI, Caregiver Strain Index (CSI), Hamilton Anxiety Rating Scale (HAM-A), Hamilton Depression Rating Scale (HAM-D),Socio-Occupational Functioning Assessment Scale (SOFAS), Family Accommodation Scale (FAS). All the above measures, along with relevant socio-demographic \& clinical variables were used evaluated as correlates of family functioning, which was measured using the OCD Family Functioning (OFF) Scale.

\section{Results}

Table-1 sample characteristics

\begin{tabular}{|c|c|c|}
\hline Patient characteristics & \multicolumn{3}{|c|}{$\% /$} \\
\hline Age Of Patient & 31.05 & 8.62 \\
\hline Gender of patient (female) & 110 & 55.0 \\
\hline Education In Years (Patient) & 12.21 & 3.30 \\
\hline Marital status of patient(married) & 104 & 52.0 \\
\hline YBOCS Obsession Score & 13.03 & 2.55 \\
\hline YBOCSCompulsion Score & 12.65 & 2.88 \\
\hline YBOCS Total Score & 25.75 & 5.39 \\
\hline Insight(YBOCSItem-11) & 1.62 & 0.66 \\
\hline Avoidance 12 & 2.26 & 0.82 \\
\hline
\end{tabular}

\begin{tabular}{|c|c|c|c|}
\hline Caregiver's Characteristitis & Mean & Median & Std. Deviation \\
\hline Education Of Caregivers In Years & 10.65 & 10.00 & 4.60 \\
\hline Individual |lnome & 24025.00 & 15000.00 & 22224.43 \\
\hline CaregiversAge & 44.78 & 45.50 & 8.99 \\
\hline Hamilton Anxiety Rating Score & 12.01 & 12.00 & 4.73 \\
\hline Hamilton Depression Rating Score & 13.71 & 13.00 & 6.07 \\
\hline Caregiver Strain IndexTotal Score & 18.59 & 20.00 & 6.14 \\
\hline Social \& Occupational Functioning Scale & 55.67 & 60.00 & 16.53 \\
\hline CORSSC(Resilience Index) & 17.22 & 16.00 & 9.09 \\
\hline FASTotal & 30.09 & 31 & 11.19 \\
\hline OFF Total Current & 54.765 & 57 & 14.81 \\
\hline OFF Fotal Worst Ever & 63.825 & 67 & 13.67 \\
\hline
\end{tabular}

\section{Table-2 Correlates of OFF}

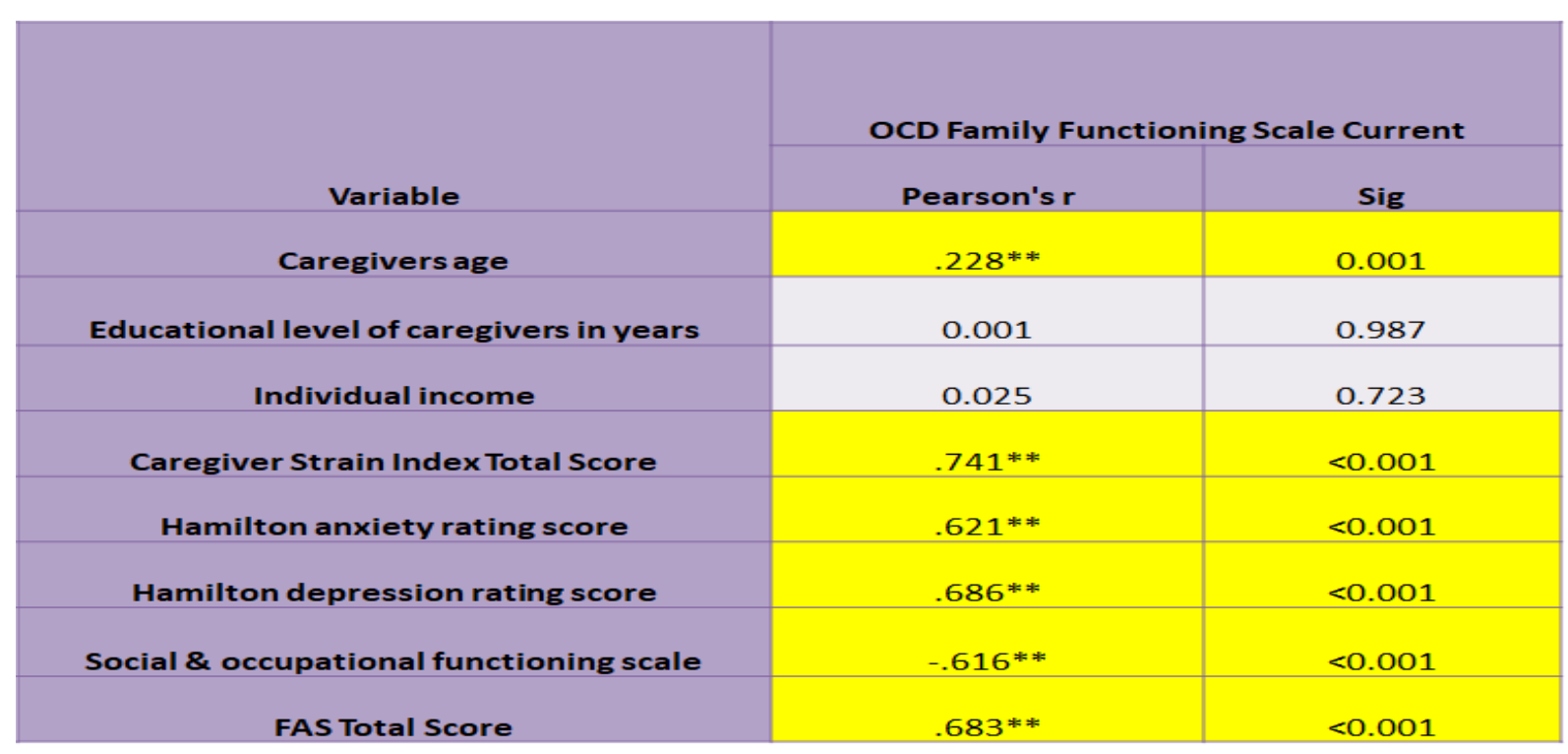

Multiple linear regression model explained $F A S(B=0.226$, $0.016), C S I,(B=0.718, P=0.001)$ and depression $(B=0.579$, $P=0.003)$ are the robust predictors of FF in caregivers

The path analysis is shown In figure-1

\section{Discussion:}

Severity of illness, contamination/washing symptoms in the patient along with severity of accommodative behaviors, caregiver stress levels, depression and anxiety symptoms in the caregiver are key determinants of family functioning impairment in OCD.

\section{Limitation}

1. The study had relied on the hospital population than the community sample

2. Emotional climate and interaction patterns within the family Social support system and personality issues did not assessed in caregivers.

\section{References:}

1. Lebowitz, E. R., Panza, K. E., Su, J., \& Bloch, M. H. (2014). Family accommodation in obsessive-compulsive disorder. Expert Rev Neurother.

2. Luckert, L. P. (2017). Family Functioning and Accommodation in Parents of Children with ObsessiveCompulsive Symptoms. Fordham University.

3. Stewart, S. E., Hu, Y.-P., Hezel, D. M., Proujansky, R., Lamstein, A., Walsh, C., . . Geller, D. A. (2011) Development and psychometric properties of the OCD Family Functioning (OFF) Scale. Journal of Family Psychology, 25(3), 434

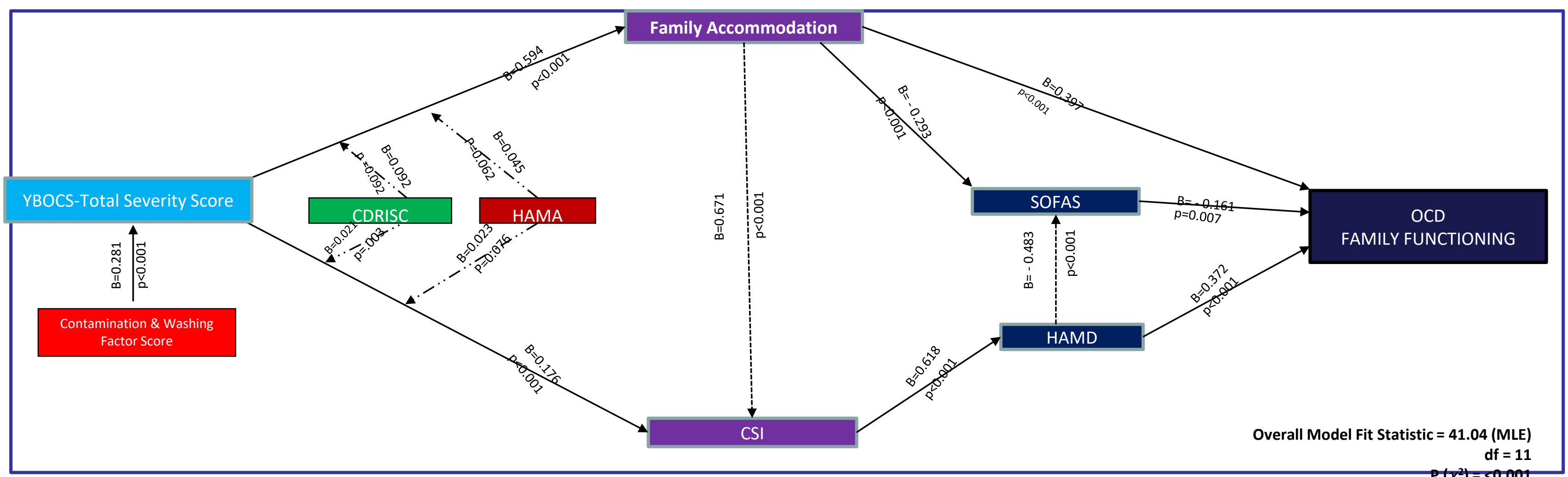

